


\title{
TRATAMENTOS FÍSICOS E QUÍMICOS PARA ACELERAR E UNIFORMIZAR A EMERGÊNCIA DE PLÂNTULAS DE Erythrina velutina Willd.
}

\author{
Valdeany Núbia de Souza ${ }^{1}$, Ariana Veras de Araújo ${ }^{2}$, Monalisa Alves Diniz da \\ Silva Camargo Pinto ${ }^{3}$, Amaury Soares de Brito ${ }^{1}$
}

1. Mestres em Produção Vegetal pela Universidade Federal Rural de Pernambuco/Unidade Acadêmica de Serra Talhada (UFRPE/UAST)

(valdeanynubia@gmail.com).

2. Mestre em Produção Vegetal pela UFRPE/UAST e Doutoranda em Agronomia/Fitotecnia pela Universidade Federal do Ceará (UFC).

3. Professora Doutora Adjunta IV da UFRPE/UAST.

Universidade Federal Rural de Pernambuco/Unidade Acadêmica de Serra Talhada (UFRPE/UAST), Caixa Postal 063, CEP 56900-000, Serra Talhada, PE, Brasil.

Recebido em: 08/04/2016 - Aprovado em: 30/05/2016 - Publicado em: 20/06/2016 DOI: 10.18677/Enciclopedia_Biosfera_2016_117

\begin{abstract}
RESUMO
O mulungu é uma arbórea com uma ampla diversidade de usos, encontrada em várzeas úmidas e a margens de rios temporários da Caatinga. Objetivou-se determinar o tratamento mais eficaz, dentre os físicos e os químicos, a ser utilizado para superação da dormência tegumentar de sementes de mulungu. $O$ experimento foi realizado em delineamento inteiramente casualizado com 12 tratamentos e cinco repetições de 20 sementes cada. Foram utilizados escarificação com lixa d'água no 80; punctura com alicate de cutícula; punctura com pirógrafo, ambos na extremidade oposta à micrópila; imersão em ácido sulfúrico 40 minutos; imersão em soda cáustica $20 \%$ por 20, 30 e 40 minutos; imersão em hipoclorito de sódio a 2,5\% por 3 , 6,12 e 24 horas e como testemunha utilizou-se sementes intactas. Os tratamentos físicos foram os que proporcionaram as maiores porcentagens de emergência de plântulas normais de mulungu, as quais diferiram dos tratamentos químicos e da testemunha. Os métodos mais eficientes para a superação da dormência tegumentar de sementes de mulungu são a escarificação com lixa e a punctura tanto com o uso de alicate de cutícula como com o pirógrafo, os quais promovem a elevação da porcentagem e a velocidade de emergência.
\end{abstract}

PALAVRAS-CHAVE: arbórea da Caatinga, dormência tegumentar, mulungu

\section{TREATMENTS PHYSICAL AND CHEMICALS TO ACCELERATE AND STANDARDISE THE SEEDLING EMERGENCE IN Erythrina velutina Willd.}

\begin{abstract}
The mulungu is a tree with a wide variety of uses, found in damp meadows and the margins of temporary rivers Caatinga. The objective was to determine the most effective treatment, among physicists and chemists, to be used to overcome the
\end{abstract}


integumentary dormancy mulungu seeds. The experiment was conducted in a completely randomized design with 12 treatments and five replications of 20 seeds each. scarification were used with sandpaper number 80; prick with cuticle nippers; pirógrafo puncture with both the end opposite to the micropyle; immersion in sulfuric acid 40 minutes; immersion in sodium hydroxide 20\% for 20, 30 and 40 minutes; immersion in sodium hypochlorite at $2.5 \%$ for $3,6,12$ and 24 hours and was used as control seeds intact. Physical treatments were those that provided the highest percentage of emergence of normal mulungu seedlings, which differed significantly from the chemical treatments and the witness. The most efficient methods to overcome dormancy integumentary mulungu seeds are scarification with sandpaper and puncture both using cuticle nippers as the pirógrafo, which promote the increase in percentage and emergency speed.

KEYWORDS: arboreal Caatinga, integumentary dormancy, mulungu

\section{INTRODUÇÃO}

O mulungu (Erythrina velutina Willd.) é uma espécie arbórea de grande porte, com flores vermelhas, frutos tipo folículo, encontrada em várzeas úmidas e a margens de rios temporários da Caatinga, ocorrendo em todo o nordeste brasileiro (SANTOS et al., 2013). A espécie é bastante utilizada para fins medicinais, madeireiros, industriais, ornamentais (GUEDES et al., 2009), e ainda na implantação de sistemas agroflorestais ou na recuperação de áreas degradadas devido ao seu crescimento rápido e rusticidade (LORENZI, 2008).

$\mathrm{Na}$ medicina, as plantas pertencentes ao gênero Erythrina são bastante conhecidas por serem fontes ricas em alcaloides e flavonoides, em particular indólico hipaforina, eritravina, 11-hidroxi-eritravina e isoflavonas (GILBERT \& FAVORETO, 2012; SILVA et al., 2013). A casca de mulungu é empregada na medicina popular devido suas propriedades sudorífica, calmante, emoliente, curativa, antimuscarínica e espasmolítica, e os frutos secos pela sua ação anestésica local. Como ornamental, o mulungu se destaca devido suas flores, sendo utilizada principalmente na arborização de ruas e jardins, além do mais, possui uma madeira leve e macia, a qual é empregada na confecção de brinquedos, jangadas, tamancos, dentre outros (LORENZI, 2008).

Apesar destes vários potenciais, existem dificuldades no estabelecimento de plantios comerciais devido à ocorrência de dormência tegumentar nas sementes. Deste modo, a dormência prolonga o tempo para que ocorra a germinação devido à alta resistência física imposta ao crescimento e desenvolvimento do embrião, prejudicando o objeto de interesse que é a produção de mudas (MATHEUS et al., 2010; SILVA et al., 2013).

Entre os inúmeros métodos utilizados para superação da dormência, destacam-se os físicos, os quais consistem na escarificação manual com lixa, punctura ou desponte do tegumento das sementes, e os químicos onde o tegumento das sementes sofre rupturas devido à ação corrosiva de substâncias como ácido sulfúrico, ácido muriático, soda cáustica, dentre outras. O uso de tais métodos aumenta a permeabilidade das sementes, permitindo a imediata embebição e o início do processo de germinação (NASCIMENTO et al., 2009).

Diante da diversidade de usos e da necessidade de se preservar a espécie, objetivou-se determinar o tratamento mais eficaz, dentre os físicos e os químicos, a ser utilizado para superação da dormência tegumentar de sementes de mulungu. 


\section{MATERIAL E MÉTODOS}

As sementes de mulungu foram coletadas em agosto de 2013 sob duas árvores matrizes, localizadas no Sítio Carro Quebrado ( $7^{\circ} 49^{\prime} 59,39^{\prime \prime} \mathrm{S}, 38^{\circ} 05^{\prime}$ $53,23 "$ O) no município de Triunfo-PE. Após a coleta, as sementes foram beneficiadas por meio das seguintes operações: remoção das sementes chochas e atacadas por insetos, acondicionamento em saco plástico e transporte para o Laboratório.

Para a superação da dormência tegumentar, as sementes foram submetidas aos seguintes tratamentos: escarificação com lixa d'água ํo 80 na extremidade oposta à micrópila; punctura com alicate de cutícula na extremidade oposta à micrópila; punctura com pirógrafo na extremidade oposta à micrópila; imersão em ácido sulfúrico por 40 minutos; imersão em soda cáustica $20 \%$ por 20,30 e 40 minutos; imersão em hipoclorito de sódio a 2,5\% por 3, 6, 12 e 24 horas e como testemunha utilizou-se sementes intactas.

As sementes tratadas quimicamente, logo depois de transcorrido o período de imersão, foram colocadas em uma peneira, lavadas em água corrente por cinco minutos até a eliminação dos produtos e secas sobre papel toalha por duas horas.

Após os tratamentos, as sementes foram semeadas em bandejas de poliestireno de 128 células contendo como substrato fibra de coco, e mantidas em condições ambientais de temperatura e umidade relativa do ar, cujas médias registradas foram em torno de $25,8 \stackrel{\circ}{\circ} \mathrm{C}$ e $56,9 \%$, respectivamente. Realizaram-se irrigações diárias para garantir a emergência e o estabelecimento das plântulas. $\mathrm{O}$ delineamento utilizado foi o inteiramente casualizado com 12 tratamentos e cinco repetições de 20 sementes cada.

Para verificar a eficiência dos tratamentos, determinou-se a porcentagem de emergência ( $P E)$ considerando como plântulas normais emergidas aquelas que apresentavam o primeiro par de folhas totalmente expandido; o índice de velocidade de emergência (IVE) foi determinado por meio de contagens diárias do número de plântulas emersas por dia, o qual foi calculado de acordo com a fórmula proposta por MAGUIRE (1962) e o tempo médio de emergência (TME), sendo este avaliado em conjunto com o teste de emergência, expresso em dias e calculado através da fórmula citada por LABOURIAU \& VALADARES (1976).

Aos 21 dias, as plântulas foram retiradas do substrato e mensuraram-se as medidas de comprimento da parte aérea (CPA) e do sistema radicular (CSR) com o auxílio de uma régua, sendo os resultados expressos em $\mathrm{cm}_{\text {plântula }}{ }^{-1}$.

Posteriormente foram retirados os cotilédones das plântulas, seccionado-se a parte aérea do sistema radicular na região do colo, e adicionando-as separadamente no interior de sacos de papel Kraft, posteriormente os materiais vegetais foram conduzidos à estufa de circulação de ar a $80{ }^{\circ} \mathrm{C}$ por 24 horas para secagem. Transcorrido esse período, procedeu-se com a pesagem da massa de matéria seca da parte aérea (MSPA) e do sistema radicular (MSSR) em balança analítica com precisão de 0,001 g, conforme recomendações de NAKAGAWA (1999). Os resultados foram expressos em g plântula ${ }^{-1}$.

Os resultados foram submetidos à análise de variância pelo teste $F$, e as médias comparadas pelo teste de Duncan a $5 \%$ de probabilidade. Para atender aos testes de normalidade e homocedasticidade, os dados referentes às variáveis massas de matéria secas da parte aérea e do sistema radicular foram transformados por meio da fórmula $\mathrm{X}=\sqrt{\mathrm{X}}$. 


\section{RESULTADOS E DISCUSSÃO}

Os dados relativos à emergência de plântulas indicaram que os tratamentos físicos foram os que proporcionaram as maiores porcentagens de emergência de plântulas normais de mulungu, as quais diferiram dos tratamentos químicos e da testemunha (Tabela 1).

Dentre os tratamentos físicos, a punctura com alicate de cutícula foi o que mais se destacou ao proporcionar $98 \%$ de plântulas emersas, seguida pela punctura com pirógrafo com $95 \%$ e a escarificação com lixa d'água com $94 \%$ de emergência, sendo que tais valores não diferiram entre si (Tabela 1). Verifica-se a eficácia destes tratamentos, pois aceleraram a retomada da atividade metabólica, a mobilização e assimilação de reversas, em consequência da ruptura do tegumento que facilitou a passagem de água e o intumescimento das sementes (MARCOS FILHO, 2005).

De acordo com SILVA et al. (2013), tanto a escarificação no lado oposto à micrópila quanto a junto a micrópila propiciaram as maiores porcentagens de emergência de plântulas de mulungu, provenientes de sementes armazenadas durante 25 meses em câmara fria e por um mês em ambiente de laboratório. Além do mais, os autores concluíram que a dormência das sementes não foi afetada pelos tipos de armazenamento.

Os tratamentos químicos proporcionaram $70 \%$ de emergência (imersão das sementes em ácido sulfúrico por 40 minutos), e $32 \%$ (imersão em hipoclorito de sódio a 2,5\% por 12 horas). A soda cáustica não ocasionou efeito satisfatório na superação da dormência tegumentar das sementes de mulungu. Possivelmente o tempo utilizado tenha sido inadequado para causar um desgaste no tegumento, que permitisse uma absorção de água suficiente para desencadear 0 processo germinativo.

O uso do hipoclorito de sódio não foi eficaz na superação da dormência e consequente emergência de plântulas. No entanto, KOBORI et al. (2013) fazendo uso desta substância averiguaram que o tratamento com hipoclorito de sódio a 2,5\% por 45 minutos foi um bom agente escarificador ao proporcionar $81 \%$ de germinação em sementes de mucuna-preta (Mucuna aterrima (Piper et Tracy)), não diferindo em relação aos tratamentos escarificação com lixa (82\%) e água quente (83\%).

Em relação ao índice de velocidade de emergência (Tabela 1) observou-se que não houve diferença entre os tratamentos que consistiram na escarificação e punctura do tegumento das sementes de mulungu. Estes tratamentos proporcionaram a emergência de aproximadamente três plântulas normais por dia. Ressalta-se que quanto mais rápido for o processo de absorção de água pelas sementes, mais vigorosas serão as plântulas devido à aceleração do processo germinativo.

Assim como foi registrado para as sementes de mulungu, a escarificação com lixa proporcionou os maiores índices de velocidade de emergência de plântulas de sesbânia (Sesbania virgata (Cav.) Pers.) (SILVA et al., 2011), de flamboyant (Delonix regia (Bojer ex Hook) Raf) (LIMA et al., 2013) e de espinho-de-Jerusalém (Parkinsonia aculeata L.) (AGRAN et al., 2015).

Com a aceleração do processo de embebição, considera-se que menor seja a quantidade de reservas energéticas gastas pelas sementes durante a emergência, fazendo com que as referidas reservas contribuam para o desenvolvimento das plântulas, fato este verificado pelo aumento da massa de matéria seca das plântulas de mulungu. Assim, NAKAGAWA (1999) salienta que o índice de velocidade de emergência é um fator imprescindível para a avaliação do vigor. 
Os resultados da avaliação do tempo médio de emergência podem ser observados na Tabela 1, os quais não diferiram entre os tratamentos. Todavia, vale ressaltar que o intervalo de tempo em que as demais plântulas levam para emergir em relação à primeira plântula normal, é um aspecto importante quando se almeja um estande de plântulas uniformes.

Tabela 1. Porcentagem de emergência (PE), índice de velocidade de emergência (IVE) e tempo médio de emergência (TME) de plântulas de Erythrina velutina Willd. oriundas de sementes submetidas à diferentes tratamentos de superação de dormência. Serra Talhada-PE, 2015

\begin{tabular}{|c|c|c|c|}
\hline \multirow{2}{*}{ Tratamentos } & PE & IVE & \multirow{2}{*}{$\begin{array}{c}\text { TME } \\
\text { (dias) }\end{array}$} \\
\hline & $(\%)$ & & \\
\hline T1 - Testemunha & $10 \mathrm{~d}$ & $0,22 \mathrm{c}$ & $2,41 \mathrm{a}$ \\
\hline $\begin{array}{l}\text { T2 - Escarificação com lixa d'água no } 80 \\
\text { na extremidade oposta à micrópila }\end{array}$ & $94 \mathrm{a}$ & $3,14 \mathrm{a}$ & $1,33 \mathrm{a}$ \\
\hline $\begin{array}{l}\text { T3 - Punctura com alicate de cutícula na } \\
\text { extremidade oposta à micrópila }\end{array}$ & $98 \mathrm{a}$ & $3,40 a$ & $1,24 \mathrm{a}$ \\
\hline $\begin{array}{l}\text { T4 - Punctura com pirógrafo na região na } \\
\text { extremidade oposta à micrópila }\end{array}$ & $95 \mathrm{a}$ & $3,38 \mathrm{a}$ & $1,20 \mathrm{a}$ \\
\hline $\begin{array}{l}\text { T5 - Imersão em ácido sulfúrico por } 40 \\
\text { minutos }\end{array}$ & $70 \mathrm{~b}$ & $1,88 b$ & $1,82 \mathrm{a}$ \\
\hline $\begin{array}{l}\text { T6 - Imersão em soda cáustica a } 20 \% \text { por } \\
20 \text { minutos }\end{array}$ & $14 \mathrm{~d}$ & $0,28 c$ & $1,98 \mathrm{a}$ \\
\hline $\begin{array}{l}\text { T7 - Imersão em soda cáustica a } 20 \% \text { por } \\
30 \text { minutos }\end{array}$ & $13 d$ & $0,24 \mathrm{c}$ & $2,26 \mathrm{a}$ \\
\hline $\begin{array}{l}\text { T8 - Imersão em soda cáustica a } 20 \% \text { por } \\
40 \text { minutos }\end{array}$ & $14 d$ & $0,25 \mathrm{c}$ & $2,30 \mathrm{a}$ \\
\hline $\begin{array}{l}\text { T9 - Imersão em hipoclorito de sódio a } \\
2,5 \% \text { por } 3 \text { horas }\end{array}$ & $14 d$ & $0,27 \mathrm{c}$ & $2,15 \mathrm{a}$ \\
\hline $\begin{array}{l}\text { T10 - Imersão em hipoclorito de sódio a } \\
2,5 \% \text { por } 6 \text { horas }\end{array}$ & $10 \mathrm{~d}$ & $0,21 \mathrm{c}$ & $1,98 \mathrm{a}$ \\
\hline $\begin{array}{l}\text { T11 - Imersão em hipoclorito de sódio a } \\
2,5 \% \text { por } 12 \text { horas }\end{array}$ & $32 \mathrm{c}$ & $0,69 \mathrm{c}$ & $2,01 \mathrm{a}$ \\
\hline $\begin{array}{l}\text { T12 - Imersão em hipoclorito de sódio a } \\
2,5 \% \text { por } 24 \text { horas }\end{array}$ & $17 \mathrm{~d}$ & $0,34 \mathrm{c}$ & $2,24 \mathrm{a}$ \\
\hline CV (\%) & 23,89 & 43,93 & 48,21 \\
\hline
\end{tabular}

Médias seguidas pela mesma letra na coluna, não diferem entre si pelo teste de Duncan ao nível de $5 \%$ de probabilidade.

Em contrapartida, PEREIRA et al. (2015) estudando tratamentos prégerminativos para a superação da dormência em sementes de ingá doce (Pithecellobium Dulce (Roxb.) Benth) obtiveram os melhores resultados quanto ao tempo médio de emergência quando submeteram as sementes a escarificação 
manual com lixa no 80 e a imersão em água por 48 horas. Em sementes de fedegoso-do-mato (Senna silvestres (Vell.) H. S. Irwin \& Barneby) a escarificação com ácido sulfúrico por três e cinco minutos se mostraram tratamentos eficazes para a redução do tempo de emergência de plântulas, quando comparado com o tempo de emergência registrado para as plântulas oriundas das sementes utilizadas como testemunha (MARANHO \& PAIVA, 2012).

Para o comprimento da parte aérea observou-se que não houve diferença no desenvolvimento da parte aérea das plântulas de mulungu, independentemente do tratamento utilizado (Tabela 2). No entanto, verificou-se uma variação de $3,77 \mathrm{~cm}$ quanto ao tamanho das plântulas provenientes das sementes não tratadas (testemunha) em relação as plântulas oriundas das sementes escarificadas com soda cáustica a $20 \%$ por 30 minutos.

Ao avaliarem alguns métodos de superação de dormência em sementes de baobá (Adansonia digitata L.), ARAÚJO et al. (2014) verificaram que o uso de soda cáustica a $30 \%$ por 30 minutos como agente escarificador incrementou 0 crescimento da parte aérea das plântulas de baobá. O comprimento médio alcançou mais de $16 \mathrm{~cm}$ por plântula.

O vigor das plântulas, baseado no crescimento do sistema radicular, mostrou que as plântulas cujas sementes sofreram escarificação química com soda cáustica a $20 \%$ por 20 minutos, foram as que proporcionaram o melhor desenvolvimento radicular, o qual diferiu do comprimento das raízes das plântulas obtidas das sementes escarificadas com soda cáustica a $20 \%$ por 30 minutos, no entanto, ambos não diferiram dos demais métodos utilizados (Tabela 2), provavelmente esta diferença se deve a quantidade de reservas das sementes e a transferência destas de forma mais eficiente ao eixo embrionário e consequentemente ao crescimento das raízes.

Para as sementes de flamboyant (Delonix regia (Bojerex Hook.) Raf.), o desponte sem e com embebição foram os tratamentos mais eficazes quanto ao comprimento do sistema radicular, em que o mesmo apresentou uma média de 7,23 e 8,53 $\mathrm{cm}$ plântula ${ }^{-1}$, respectivamente (CÂMARA et al., 2015).

Os maiores conteúdos de massa de matéria seca tanto da parte aérea quanto do sistema radicular foram registrados nas plântulas oriundas das sementes escarificadas com lixa d'água no 80 e por meio da punctura com alicate de cutícula. Estes tratamentos diferiram dos obtidos com as plântulas provenientes das sementes submetidas à imersão em soda cáustica por 40 minutos e hipoclorito de sódio (2,5\%) por três e seis horas (Tabela 2$)$.

Acredita-se que essas maiores taxas de ganho de massa de matéria seca se deve a capacidade de transformação dos tecidos de reservas armazenadas e a aceleração do processo de embebição pelas sementes devido a ruptura do tegumento reduzindo a utilização de energia nessa fase e com isso há um maior investimento no desenvolvimento e na assimilação de nutrientes pelas plântulas.

A busca por uma metodologia mais eficaz, prática e de baixo custo para superação da dormência em sementes de chichá (Sterculia foetida L.) resultou na indicação de métodos de superação de dormência capazes de proporcionar plântulas com maior massa de matéria seca de parte aérea. Destacaram-se a escarificação das sementes em um dos lados com lixa no 40 por 3 minutos, seguida de embebição por 24 horas, o qual diferiu dos resultados proporcionados com a escarificação nos dois lados da sementes, seguido de embebição e da escarificação em um lado da sementes sem embebição (SANTOS et al. 2004). 
Resultados semelhantes foram observados com sementes de faveira (Parkia platycephala Benth) submetidas a escarificação com lixa, as quais também originaram plântulas com maior conteúdo de massa de matéria seca do sistema radicular (NASCIMENTO et al., 2009). Em contrapartida, OLIVEIRA et al. (2012) mostraram que os tratamentos de escarificação química por meio da imersão das sementes de fava barriguda (Parkia gigantocarpa Ducke) em ácido sulfúrico (98\%) por 30 e 40 minutos, foram os mais eficazes ao proporcionar as maiores médias de alocação de massa de matéria seca na raiz primária.

Tabela 2. Comprimento da parte aérea (CPA), comprimento do sistema radicular (CSR), massa de matéria seca da parte aérea (MSPA) e massa de matéria seca do sistema radicular (MSSR) de plântulas de Erythrina velutina Willd. oriundas de sementes submetidas à diferentes tratamentos. Serra Talhada-PE, 2015

\begin{tabular}{|c|c|c|c|c|}
\hline \multirow{2}{*}{ Tratamentos } & CPA & CSR & MSPA & MSSR \\
\hline & \multicolumn{2}{|c|}{ cm plântula ${ }^{-1}$} & \multicolumn{2}{|c|}{ g plântula ${ }^{-1}$} \\
\hline T1 - Testemunha & $12,00 \mathrm{a}$ & $7,90 a b$ & $0,66 d$ & $0,28 \mathrm{c}$ \\
\hline $\begin{array}{l}\text { T2 - Escarificação com lixa d'água no } \\
80 \text { na extremidade oposta à micrópila }\end{array}$ & $14,93 \mathrm{a}$ & $9,74 a b$ & $3,38 \mathrm{a}$ & $1,09 a$ \\
\hline $\begin{array}{l}\text { T3 - Punctura com alicate de cutícula } \\
\text { na extremidade oposta à micrópila }\end{array}$ & $14,76 \mathrm{a}$ & $9,13 a b$ & $3,05 \mathrm{a}$ & $1,09 a$ \\
\hline $\begin{array}{l}\text { T4 - Punctura com pirógrafo na região } \\
\text { na extremidade oposta à micrópila }\end{array}$ & $13,66 \mathrm{a}$ & $8,48 a b$ & $1,85 \mathrm{bc}$ & $0,86 a b$ \\
\hline $\begin{array}{l}\text { T5 - Imersão em ácido sulfúrico por } 40 \\
\text { minutos }\end{array}$ & $14,20 \mathrm{a}$ & $7,71 \mathrm{ab}$ & $2,15 b$ & $0,70 a b$ \\
\hline $\begin{array}{l}\text { T6 - Imersão em soda cáustica a } 20 \% \\
\text { por } 20 \text { minutos }\end{array}$ & $15,03 \mathrm{a}$ & $11,72 \mathrm{a}$ & $1,00 \mathrm{~cd}$ & $0,40 \mathrm{c}$ \\
\hline $\begin{array}{l}\text { T7 - Imersão em soda cáustica a } 20 \% \\
\text { por } 30 \text { minutos }\end{array}$ & $15,77 \mathrm{a}$ & $5,91 \mathrm{~b}$ & $0,99 \mathrm{~cd}$ & $0,46 \mathrm{bc}$ \\
\hline $\begin{array}{l}\text { T8 - Imersão em soda cáustica a } 20 \% \\
\text { por } 40 \text { minutos }\end{array}$ & $14,38 \mathrm{a}$ & $9,38 a b$ & $0,87 d$ & $0,38 \mathrm{c}$ \\
\hline $\begin{array}{l}\text { T9 - Imersão em hipoclorito de sódio } \\
2,5 \% \text { por } 3 \text { horas }\end{array}$ & $13,48 a$ & $10,89 a b$ & $0,70 \mathrm{~d}$ & $0,42 \mathrm{c}$ \\
\hline $\begin{array}{l}\text { T10 - Imersão em hipoclorito de sódio } \\
2,5 \% \text { por } 6 \text { horas }\end{array}$ & $14,22 \mathrm{a}$ & $9,99 a b$ & $0,73 d$ & $0,44 \mathrm{c}$ \\
\hline $\begin{array}{l}\text { T11 - Imersão em hipoclorito de sódio } \\
2,5 \% \text { por } 12 \text { horas }\end{array}$ & $15,32 \mathrm{a}$ & $8,44 a b$ & $1,03 \mathrm{~cd}$ & $0,47 \mathrm{bc}$ \\
\hline $\begin{array}{l}\text { T12 - Imersão em hipoclorito de sódio } \\
2,5 \% \text { por } 24 \text { horas }\end{array}$ & $14,80 \mathrm{a}$ & $9,61 a b$ & $0,95 \mathrm{~cd}$ & $0,56 \mathrm{bc}$ \\
\hline CV (\%) & 18,14 & 37,50 & 45,15 & 48,05 \\
\hline
\end{tabular}

Médias seguidas pela mesma letra na coluna, não diferem entre si pelo teste de Duncan ao nível de $5 \%$ de probabilidade. 


\section{CONCLUSÃO}

Os tratamentos físicos por meio da escarificação com lixa d'água ํo 80 e da punctura tanto com o uso de alicate de cutícula como com o pirógrafo, são eficientes para promover a superação da dormência tegumentar das sementes de mulungu, promovendo a elevação da porcentagem e da velocidade de emergência das plântulas.

\section{AGRADECIMENTOS}

Ao Programa de Pós-Graduação em Produção Vegetal da Universidade Federal Rural de Pernambuco/Unidade Acadêmica de Serra Talhada (UFRPE/UAST).

\section{REFERÊNCIAS}

AGRAN, P. F. M.; GUEDES, R. S.; SILVA, M. L. M.; SOUZA, V. C.; ANDRADE, L. A.; ALVES, E. U. Métodos para superação da dormência de sementes de Parkinsonia aculeate L. Semina: Ciências Agrárias, v. 36, n. 3, p. 1191-1202, 2015. Disponível em: <http://www.uel.br/revistas/uel/index.php/semagrarias/article/view/12408>. doi: 10.5433/1679-0359.2015v36n3p1191.

ARAÚJO, A. V.; PINTO, M. A. D. S.; BRITO, A. C. V.; BRITO, A. S.; SOUZA, V. N. Métodos alternativos para a superação de dormência de sementes de Adansonia digitata L. Enciclopédia Biosfera, v. 10, n. 18, p. 2165-2173, 2014.

CÂMARA, F. M. M.; PEREIRA, E. C.; CARNEIRO, J. V.; OLIVEIRA, H. T. B.; SILVA, R. M.; PEREIRA, G. A. Métodos alternativos na superação de dormência em sementes de flamboyant. Agropecuária Científica no Semiárida, v. 11, n. 3, p. 76-83, 2015.

GILBERT, B.; FAVORETO, R. Erythrina sp. Fabaceae (Leguminosae, Faboideae), Revista Fitos, v. 7, n. 3, p. 185-197, 2012.

GUEDES, R. S.; ALVES, E. U.; GONÇALVES, E. P.; VIANA, J. S.; MEDEIROS, M. S.; LIMA, C. R. Teste de comprimento de plântulas na avaliação da qualidade fisiológica de sementes de Erythrina velutina Willd. Semina: Ciências Agrárias, v. 30, n. 4, p. 793-802, 2009.

Disponível

em: <http://www.uel.br/revistas/uel/index.php/semagrarias/article/view/4074>. 10.5433/1679-0359.2009v30n4p793.

KOBORI, N. N.; MASCARIN, G. M.; CICERO, S. M. Métodos não sulfúricos para superação de dormência de sementes de mucuna-preta (Mucuna aterrima). Informativo ABRATES, v. 23, n. 1, p. 25-32, 2013.

LABOURIAU, L. G.; VALADARES, M. E. B. On the germination of seeds Calotropis procera (Ait.) Ait. f. Anais da Academia Brasileira de Ciências, v. 48, n. 2, p. 263-284, 1976.

LIMA, J. S.; CHAVES, A. P.; MEDEIROS, M. A.; RODRIGUES, G. S. O.; BENEDITO, C. $P$. Métodos de superação de dormência em sementes de flamboyant (Delonix regia). Revista Verde de Agroecologia e Desenvolvimento Sustentável, v. 8, n. 1, p. 104-109, 2013. 
LORENZI, H. Árvores Brasileiras: Manual de Identificação e Cultivo de Plantas Arbóreas Nativas do Brasil, v. 01, 5a ed. Nova Odessa, São Paulo: Instituto Plantarum, 2008. 384p.

MAGUIRE, J. D. Speed of germination-aid in and evaluation for seedling emergence and vigour. Crop Science, v. 2, n. 1, p. 176-177, 1962.

MARANHO, A. S.; PAIVA, A. V. Superação de dormência tegumentar em sementes de Senna silvestres (Vell.) H. S. Irwin \& Barneby, Revista Biotemas, v. 25, n. 2, p. 25-31, 2012. Disponível em: <https://periodicos.ufsc.br/index.php/biotemas/issue/view/1768>. doi: 10.5007/2175-7925.2012v25n2p25.

MARCOS FILHO, J. Fisiologia de Sementes de Plantas Cultivadas, v. 12, Fundação de Estudos Agrários Luiz de Queiroz-FEALQ, Piracicaba-SP, 2005. 495p.

MATHEUS, M. T.; GUIMARÃES, R. M.; BACELAR, M.; OLIVEIRA, S. A. S. Superação da dormência em sementes de duas espécies de Erythrina. Revista Caatinga, v. 23, n. 3, p. 48-53, 2010.

NAKAGAWA, J. Teste de vigor baseados no desempenho das plântulas. In: KRZYZANOWSKI, F. C.; VIEIRA, R. D.; FRANÇA NETO, J. B. (Eds). Vigor de sementes: conceitos e teses. Associação Brasileira de Tecnologia de Sementes, Comitê de Vigor de Sementes. Londrina: ABRATES, 1999.

NASCIMENTO, I. L.; ALVES, E. U.; BRUNO, R. L. A.; GONÇALVES, E. P.; COLARES, P. N. Q.; MEDEIROS, M. S. Superação da dormência em sementes de faveira (Parkia platycephala Benth). Revista Árvore, v. 33, n. 1, p. 35-45, 2009. Disponível em: <http://www.scielo.br/scielo.php?script=sci_arttext\&pid=S0100-67622009000100005>. doi: 10.1590/S0100-67622009000100005.

OLIVEIRA, A. K. M.; RIBEIRO, J. W. F.; PEREIRA, K. C. L.; RONDON, E. V.; BECKER, T. J. A.; BARBOSA, L. A. Superação de dormência em sementes de Parkia gigantocarpa (Fabaceae-Mimosidade), Ciência Florestal, v. 22, n. 3, p. 533-540, 2012.

PEREIRA, F. E. C. B.; GUIMARÃES, I. P.; TORRES, S. B.; BENEDITO, C. P. Superação de dormência em sementes de Pithecellobium Dulce (Roxb.) Benth. Semina: Ciências Agrárias, v. 36, n. 1, p. 165-170, 2015. Disponível em: <http://dx.doi.org/10.5433/16790359.2015v36n1p165>. doi: 10.5433/1679-0359.2015v36n1p165

SANTOS, T. O.; MORAIS, T. G. O.; MATOS, V. P. Escarificação mecânica em sementes de chichá (Sterculia foetida L.), Revista Árvore, v. 28, n. 1, p. 1-6, 2004.

SANTOS, L. W.; COELHO, M. F. B.; AZEVEDO, R. A. B.; LIMA, A. K. B.; SOUZA, J. W. N. Erythrina velutina Willd. - Fabaceae: árvore de múltiplos usos no nordeste brasileiro. Revista Verde de Agroecologia e Desenvolvimento Sustentável, v. 8, n. 5, p. 72-80, Edição Especial, 2013.

SILVA, P. E. M.; SANTIAGO, E. F.; DALOSO, D. M.; SILVA, E. M.; SILVA, J. O. Quebra de dormência em sementes de Sesbania virgata (Cav.) Pers. Idesia, v. 29, n. 2, p. 39-45, 
2011. Disponível em: <http://www.scielo.cl/scielo.php?script=sci_arttext\&pid=S071834292011000200005>. doi: 10.4067/S0718-34292011000200005.

SILVA, L. W.; COELHO, M. F. B.; MAIA, S. S. S.; SILVA, R. C. P.; CÂNDIDO, W. S.; SILVA, A. C. Armazenamento e métodos para a superação da dormência de sementes de mulungu. Semina: Ciências Agrárias, v. 34, n. 1, p. 171-178, 2013. Disponível em: <http://www.uel.br/revistas/uel/index.php/semagrarias/article/view/8187>. 10.5433/1679-0359.2013v34n1p171.

SILVA, D. S. B. S.; BARBOZA, B.; GARCIA, A. C. F. S.; OLIVEIRA, B.; ESTEVAM, C. S.; NETO, V. A.; SANTOS, A. L. L. M.; DIAS, A. S.; SCHER, R.; PANTALEAO, S. M. Investigation of protective effects of Erythrina velutina extract against MMS induced damages in the root meristema cells of Allium cepa. Revista Brasileira de Farmacognosia, v. 23, n. 2, p. 273-278, 2013. Disponível em: < http://www.sciencedirect.com/science/article/pii/S0102695X1370036X>. doi: 10.1590/S0 102-695X2013005000006. 